\title{
Morbidade Hospitalar por Hanseníase em Minas Gerais: um estudo epidemiológico no período de 2008 a 2015
}

Rayane Evelin Brito Marques, Laís Ciribelli YamCiribelliaguchi, Jéssica Aline Silva Soares, Daniela Pimenta De Castro Fernandes, Waneska Alexandra Alves

\begin{abstract}
Resumo
A hanseníase é uma doença crônica, infectocontagiosa, de alta infectividade e baixa patogenicidade. Manifesta-se principalmente através de sinais e sintomas dermatoneurológicos, caracterizados por lesões na pele e nos nervos periféricos, podendo ocasionar deformidades físicas. O Brasil ocupa a segunda posição em número de casos novos, sendo que Minas Gerais demanda monitorização, por apresentar municípios com elevada endemicidade. Historicamente no país, o controle da hanseníase esteve atrelado a práticas discriminatórias, com internação compulsória e isolamento dos doentes, as quais foram legalmente abolidas. No presente não existe informação significativa a respeito desse tipo de terapia, sabe-se, porém, que a internação é recomendada somente em situações extremas. O Ministério da Saúde (MS) possui o Sistema de Informação Hospitalar (SIH/SUS) que tem como função registrar todos os procedimentos hospitalares de estabelecimentos conveniados ao Sistema Único de Saúde (SUS). Descrever os casos internados por hanseníase e sequelas de hanseníase, em Minas Gerais, no período de 2008 a 2015, como forma de ampliar o volume de informações sobre o tema e alavancar discussões sobre a importância de medidas efetivas para controle da patologia. Foi realizado estudo descritivo com dados secundários públicos retrospectivos disponibilizados no endereço eletrônico do Departamento de Informática do SUS (Datasus/MS). Foram utilizados casos de internação por hanseníase ou sequela de hanseníase registrados no SIH/SUS. As variáveis analisadas foram: ano da internação, macrorregião de saúde (MRS), caráter de atendimento, valor total das internações, faixa etária e sexo. Foram calculados o coeficiente de internação $(\mathrm{CI})\left(\mathrm{n}^{\circ}\right.$ de casos/população residente* 100 mil habitantes) e o intervalo de confiança (IC95\%). No estado de Minas Gerais foram notificados 2.196 casos de internações no período estudado. O CI médio foi de 1,4 casos internados/100 mil hab. (IC95\% 0,9-1,9). A MRS com maior número de internações foi a MRS Leste do Sul com 27\% (598). O risco de internação para essa MRS foi 11,0 casos internados/100 mil hab. (IC95\% 4,3-17,6). A distribuição, segundo sexo, revela diferença importante entre masculino e feminino, sendo $67 \%$ (1.481) e $33 \%$ (715), respectivamente. A faixa etária entre 30 e 49 anos foi a mais frequente com 34\% (746) das internações. Os menores de 15 anos representam 4\% (88) do total de internados. Quanto à cor/raça, observou-se predomínio da cor negra (preta+parda) com 54\% (1.193), seguida da branca 25\% (544). 19\% (426) não tinham informação. Por fim, constatou-se que o caráter de urgência tem maior expressividade, $73 \%$ (1.601), e o valor total gasto com as internações foi $\mathrm{R} \$ 1.419 .828,48$. Apesar da baixa letalidade da doença, o presente estudo confirmou a relevância da ocorrência de internações hospitalares por causas relacionadas à hanseníase, especialmente por complicações decorrentes da doença. É notória a identificação crescente de internações de 2008 a 2015. O sistema de saúde (SUS) e os profissionais inseridos nele devem atuar com o objetivo de minimizar as internações desses pacientes, atuando principalmente na atenção primária. São necessárias ações que sejam voltadas para a adesão desses pacientes ao tratamento efetivo e para o diagnóstico precoce.
\end{abstract}

Descritores: Hanseníase; Epidemiologia descritiva; Análise de dados. 